\title{
The Role of Regulatory Focus in the Experience and Self-Control of Desire for Temptations
}

\author{
Utpal M. Dholakia \\ Rice University \\ Mahesh Gopinath \\ Old Dominion University \\ Richard P. Bagozzi \\ University of Michigan \\ Rajan Nataraajan \\ Auburn University
}

\begin{abstract}
This research examines the role of regulatory focus in the experience and control of desire for temptations, the fulfillment of which conflicts with other salient goals of the consumer. Relative to a prevention focus (i.e., an orientation away from negative outcomes), our findings demonstrate that a promotion focus (i.e., an orientation toward positive outcomes) not only increases the intensity of desire experienced on encountering a temptation, but also increases success of its subsequent resistance. Differences in self-control efficacy are found to be mediated by the type of self-control strategies consumers use in the 2 foci. Convergent evidence obtained in 4 studies, considering situational and dispositional aspects of regulatory focus, indicates that when temptations are encountered by consumers, regulatory focus is an important determinant of the degree of desire, and the nature and outcome of self-control.
\end{abstract}

A calorie-conscious man standing in the cafeteria line to buy a salad sees a mouth-watering piece of New York cheesecake. A financially constrained shopper receives a preapproved offer to apply for yet another credit card. A student studying for her exams receives a call from a friend inviting her to a party that evening. In each case, the individual is likely to experience a desire to act: to buy the cheesecake, apply for the credit card, and go to the party. Yet most people would try to control these desires because they contradict and prevent the achievement of important current goals that they are pursuing: to maintain one's weight; remain debt free; and get good grades, respectively (e.g., Ainslie, 1992; Fishbach, Friedman, \& Kruglanski, 2003). A large body of existing literature on self-control (Baumeister, Heatherton, \& Tice, 1994; Carver \& Scheier, 1998; Tice, Bratlavsky, \& Baumeister, 2001) has shown that owing to various factors, some individuals are able to resist

Correspondence should be addressed to Utpal M. Dholakia, Rice University, Jesse H. Jones Graduate School of Management, 6100 Main Street, Houston, TX 77005-1892 .E-mail: dholakia@ rice.edu such temptations, whereas others succumb to them. Even the same consumer may be able to resist a particular temptation at some times, but fail to do so at other times.

Our research explores one determinant of the experience and the self-control of temptations: the consumer's regulatory focus. Building on the hedonic principle, which is the idea that motivations to approach pleasure and to avoid pain are fundamental inputs to behavior (James, 1890; Lewin, 1951), Higgins' regulatory focus theory proposes that two distinct motivational systems, with different strategic means for self-regulation, guide behavior (Aaker \& Lee, 2001; Higgins, 1999, 2002; Higgins \& Spiegel, 2004). One system employing strategic means that are approach oriented is the promotion focus. The other uses means that are avoidance oriented and is the prevention focus. These two foci also differ in how goals and tasks are framed by consumers, their affinities toward risk, and their favored styles of processing information (Friedman \& Förster, 2001; Higgins, 2002; Liberman, Idson, Camacho, \& Higgins, 1999; Liberman, Molden, Idson, \& Higgins, 2001). 
In this research, we study how regulatory focus influences the experience of desire for temptations and the desire's resistance by consumers. In four studies, our findings consistently reveal that intensity of experienced desire is greater in the promotion relative to the prevention focus. How the self-control task is framed, and which strategies are used to control behavior, also vary in the two cases, leading to more effective self-control for those with a promotion focus relative to a prevention focus. The theory and the hypotheses underlying these findings are presented first followed by the description of the studies and their results.

\section{THEORETICAL FRAMEWORK AND RESEARCH HYPOTHESES}

Consumers commonly encounter temptations in everyday life such as alluring but unaffordable garments, seemingly enticing but ultimately vacuous television programs, and luscious but calorific desserts. On experiencing desire for such temptations, both the end state from the desire's fulfillment and the interfering (and conflicting) alternative goals become salient to these individuals (Carver \& Scheier, 1998; Miller, 1951). Indeed, it is the awareness of this conflict that makes a temptation a temptation (Fishbach et al., 2003; Hoch \& Loewenstein, 1991).

Our interest is in studying those instances in which cognizance of the conflict leads the consumer to try resisting the temptation (e.g., Baumeister et al., 1994). Consumers can use various strategies to exert self-control. They may monitor savings or dieting programs through weekly budgets-financial or dietary. Some consumers may focus attention on other stimuli and away from the temptation; others may reward themselves with smaller, less-pernicious options instead; and still others may keep their attention and interest focused on the task of resistance (Ainslie, 1992).

Our main proposition is that the consumer's regulatory focus plays an important role in both the degree to which he or she experiences desire for temptations and how effectively desire is controlled. To develop this idea in depth, consider the following differences between the promotion and prevention foci, as postulated by regulatory focus theory (Higgins, 1999, 2002; Higgins \& Spiegel, 2004). First, behavior is regulated through different means in the two foci. In the promotion focus, the individual's actions are governed by ideals; that is aspirations and accomplishments that he or she would like to achieve and strive for. In contrast, the prevention focus regulates behavior through a preoccupation on oughts; that is, duties and responsibilities. These foci have been shown by biopsychologists to have distinct physiological bases (e.g., Gray, 1990).

Second, there are differences in how goal pursuit is framed in the two foci. Promotion focused individuals favor approach strategies, so they frame goal pursuit in terms of gains and nongains; prevention focused individuals do so with respect to losses and nonlosses because of their prefer- ence for avoidance strategic means (Aaker \& Lee, 2001). Under a promotion focus, the individual's strategic inclination is to approach matches to end states he or she would like to achieve (Higgins, 1999). Such individuals are more eager to avoid errors of omission (i.e., missing an emerging opportunity to accomplish something), resulting in an initial inclination to act (Crowe \& Higgins, 1997). In contrast, a prevention focus fosters a tendency to avoid mismatches to end states he or she would like to attain, with an orientation toward maintaining the status quo and shielding oneself from losses. Such individuals therefore prefer cognitive or behavioral courses that avoid errors of commission (i.e., making mistakes). These differences have been shown to result in a more explorative information processing style by promotion focused individuals (Friedman \& Förster, 2001), more openness to change (Liberman et al., 1999), and a risky decision bias marked by use of less stringent criteria in decision making (Crowe \& Higgins, 1997) in comparison to prevention focused individuals.

The third important difference between the regulatory foci concerns motivational differences. Prior research has shown that promotion focused individuals have higher motivation levels than prevention focused individuals. This difference is evident in greater persistence in goal pursuit by promotion focused individuals (Roney, Higgins, \& Shah, 1995), greater ability to bounce back and perform after a failure experience rather than quitting (Crowe \& Higgins, 1997), greater capacity to change plans and use alternative strategies during goal pursuit (Higgins \& Spiegel, 2004), and higher standards of attainment that raise performance in effortful tasks (Higgins, 2002) relative to prevention focused individuals.

\section{The Effects of Regulatory Focus on the Experience of Desire and Self-Control for Temptations}

Consider the effects of exposure to a desire-causing temptation, such as a slice of cheesecake or a designer sweater, on consumers under these two regulatory foci. We expect that an orientation of open mindedness, the preference for change, and risk seeking fostered by the promotion focus will be conducive to triggering greater desire initially for the cheesecake or sweater. In contrast, an orientation of risk aversion-preference for stability and caution supported by the prevention focus - is likely to hinder the experience of desire. Pham and Avnet's (2004) research supported such an expectation by showing that promotion focused consumers give more weight to positive affective cues, whereas prevention focused consumers attend more to substantive information. Consequently, we predict that those with a promotion focus will experience a greater intensity of desire for the temptation than those with a prevention focus. To test this hypothesis, we conducted a field study in which regulatory focus of participants was first manipulated, and then differences in desire for cheesecake between promotion and prevention focused consumers were examined. 
In Study 2, we examine differences in self-control between the groups. Both studies were designed to demonstrate occurrence of the effects; the underlying processes are examined in Studies 3 and 4.

\section{STUDY 1: REGULATORY FOCUS AND DESIRE EXPERIENCE FOR A TEMPTATION}

\section{Method}

Participants and procedure. As a partial fulfillment of course requirements, 46 undergraduate students participated in the experiment. This study was purportedly conducted in two unrelated stages. The participant's regulatory focus was primed in the first phase through essay writing. Following this manipulation, participants were invited to participate in a taste test in an adjoining room, and were told that they would receive one of several food items for tasting and evaluation. On entering the adjacent room, each participant was shown a slice of cheesecake.

Participants reported the level of desire they experienced for it, and were then allowed to taste and eat as much of the cheesecake slice as they wished. Finally, they completed a number of evaluative measures regarding the cheesecake, were thanked for their participation, debriefed, and dismissed.

Manipulation of regulatory focus. Participants were randomly assigned to either promotion or prevention focused conditions. Regulatory focus was manipulated through essay writing. Those assigned to the promotion focus condition wrote an essay on the concept of achievement and advancement by writing in support of the principle: "Success in life is determined by action, not inaction." Those in the prevention focus condition wrote an essay on the concept of security and caution by supporting the principle: "Prevention is the best form of cure." Essays were judged for adequacy by two coders, blind to the hypotheses. An essay was deemed as adequate if it contained at least five sentences in support of the assigned principle. All respondents were deemed to have completed the essay.

Measure of desire. Desire was measured using the following item: "My desire for eating the cheesecake at this moment can be described as ." To answer, participants used a 7-point scale ranging from 1 (no desire at all) to 7 (very strong desire), with the middle being (a moderate desire).

\section{Results}

Results of an analysis of variance supported our prediction regarding experience of desire for temptations, because those in a promotion focus condition $(M=5.0)$ reported greater de- sire for eating the cheesecake than those in the prevention focus condition $(M=4.3), F(1,44)=4.75, p<.05$.

\section{Discussion}

Next consider consumers in the two regulatory focus conditions after they have experienced desire for the temptation. Regardless of regulatory focus, all consumers will try to control their actions by resisting the temptation. Prior research findings (described previously) that promotion focused individuals are more motivated to remain engaged in and pursue effortful goals lead us to predict that they should be better able to resist the desire by exerting self-control when compared to prevention focused individuals. Study 2 was conducted to test this hypothesis. In this study, after manipulating regulatory focus, we examined self-control differences between consumers engaged in weight-loss regimens.

\section{STUDY 2: REGULATORY FOCUS AND SELF-CONTROL FOR A TEMPTATION}

\section{Method}

\section{Participants and Procedure}

Participants were 44 undergraduate students who were following a low-calorie weight-loss regimen. They were recruited by posting flyers at various places on the campus of a large university and advertising on public announcement television screens on its campus. The recruitment message invited participation in a taste-test study for those currently actively engaged in a weight loss regimen and offered $\$ 10$ for participation. Current participation in the regimen was verified again when participants arrived for the study. Four recruits were disqualified at this time because they were not actively dieting.

Similar to Study 1, this experiment was conducted in two stages. The participant's regulatory focus was primed in the first phase through essay writing, using the same procedure as Study 1. Following this manipulation, participants were invited to participate in a taste test of various food items in a separate room where self-control was measured in two different ways. On entering the room where the taste test was conducted, respondents were instructed:

In this study, we would like you to help us by evaluating one or more of several different food products. Many of these products are rich and high in calories. When conducting the taste test, participants usually eat the whole serving, for example, a slice of cheesecake or a cup of pudding, and then provide their opinions regarding its taste, texture, creaminess, aftertaste, etc.

The procedure used in this study will be as follows: First, we will ask you to choose the products you would like to taste test from a list of products that we are evaluating. You may 
pick as many products from this list to taste test as you like. Then, we will randomly select one or more of the products from your list (or others, if your preferred product(s) are not available). You will then be asked to taste test each product by eating the serving and then answering a number of questions regarding the product.

The participants were then given a list of 12 food items. One half of these (6) were tempting and high in calories, and the remaining 6 were low in calories. Participants could select as many of the items to taste as they liked, by checking boxes on the list. After completing this task, all respondents were informed that they had been randomly selected to taste a slice of cheesecake. They were then given a cheesecake slice, and prior to tasting, they were asked to complete measures of self-control and behavioral intentions. ${ }^{1}$

\section{Measures}

List of food options for taste test. The high-calorie food options were (a) cheesecake, (b) decadent black forest trifle, (c) double chocolate mocha trifle, (d) fantasy fudge in a cloud, (e) chocoholics delight, and (f) hot fudge ice cream bar dessert. The low-calorie food options were (a) apple and sunflower seed salad, (b) crackers, (c) veggie crisps, (d) oat bran sticks, (e) celery and carrot stick snack, and (f) low-fat rice cakes. High- and low-calorie options were alternated in the list. ${ }^{2}$

Self-control and behavioral intentions. Self-control was measured with, "I am resisting the urge to eat the cheesecake." Behavioral intentions were measured using the item, "I will certainly eat the whole serving of cheesecake." Both items used a 7-point scale ranging from 1 (strongly disagree) to 7 (strongly agree).

\section{Results}

Note that all participants were dieting and therefore should view the eating of high-calorie items as temptations to be resisted. Our hypothesis was that participants with a promotion focus should be able to exert self-control under such circumstances to a greater extent than prevention focus participants.

\footnotetext{
${ }^{1}$ It is worth noting that we had also planned to measure actual consumption of the cheesecake and use it as an additional dependent variable. However, virtually all participants ate at least a mouthful of cheesecake, and some requested the experimenter to take it with them to snack on later. The experimenter (blind to the hypotheses) agreed to such requests. Furthermore, poststudy debriefings also indicated that several respondents felt obligated to taste the cheesecake. For these reasons, we were not able to measure and report actual cheesecake consumption of participants meaningfully.

${ }^{2}$ The selection of the high-calorie and low-calorie options was based on a pretest conducted with a separate sample of 25 undergraduate students. In the pretest, participants were given a list of 18 food items and were asked to rate each on a 7-point scale, ranging from 1 (very low calorie) to 7 (very high calorie). We selected the 6 most extreme high-calorie options $(M=6.5)$ and the 6 most extreme low-calorie options ( $M=1.94$ ) based on these evaluations.
}

We tested this hypothesis with participants' food item choices as well as their reports of self-control.

\section{Choice of Food Items}

Promotion focus participants selected significantly fewer $(M=1.13)$ high-calorie items to taste when compared to those with a prevention focus $(M=2.10), F(1,43)=9.25, p<.01$, supporting our hypothesis. However, both promotion $(M=$ 1.61) and prevention focus participants $(M=1.71)$ chose about the same number of low calorie items, $F(1,43)=.05, n s$.

\section{Self-Control and Behavioral Intentions}

For the self-control measure, the results revealed that those with a promotion focus were significantly higher $(M=$ 4.13) than those with a prevention focus $(M=2.48), F(1,43)$ $=8.90, p<.01$. They also reported lower behavioral intentions to eat the entire serving of the cheesecake $\left(M_{\text {promotion }}=\right.$ 3.22 vs. $\left.M_{\text {prevention }}=5.19\right), F(1,43)=9.20, p<.01$.

\section{Discussion}

The participants' choices as well as the self-control and behavioral intentions measures support our hypothesis that those with a promotion focus are able to engage in self-control to a greater degree than prevention focus participants. Taken together with the results of Study 1, these results imply that promotion focus individuals not only experience greater desire initially, but are then able to control it more effectively.

Despite the supportive findings of the two studies, two of their limitations must be noted. First is that Studies 1 and 2 did not address questions of process. In particular, they did not examine why promotion focus individuals are better able to resist desires than those with a prevention focus. It could be because they use more self-control strategies or different self-control strategies (or both) than prevention focus individuals. Second, in addition to being situationally induced, regulatory focus has also been treated as a dispositional variable in prior research (e.g., Higgins \& Spiegel, 2004; Liberman et al., 2001), which we did not consider in the first two studies. Accordingly, in Study 3, we consider the role of regulatory focus as a dispositional variable and study differences in desire experience and self-control jointly among promotion and prevention focus individuals. Processes underlying observed differences are explored in Study 3 and examined in depth in Study 4, in which regulatory focus was manipulated as in the first two studies.

\section{STUDY 3: CHRONIC REGULATORY FOCUS AND PROCESSES UNDERLYING DESIRE EXPERIENCE AND SELF-CONTROL}

This study was designed to replicate the results of the first two studies-greater desire experience among promotion focus individuals in Study 1, and greater self-control among promotion focus individuals in Study 2-within a single 
study. We do so by considering the role of regulatory focus as a dispositional variable, operationalizing it through individual difference scales (Carver \& White, 1994). We also study processes underlying observed differences in desire experience and self-control among promotion and prevention focus individuals.

Adopting an individual difference lens and corroborated by considerable evidence from the physiology of neurobiological functioning (see Carver \& Scheier 1998, pp. $167-170$ for a review), Gray (1990) proposed that two self-regulatory systems underlie affect and behavior. The behavioral activation system (BAS) controls appetitive motivation and is responsive to positive outcomes, whereas the behavioral inhibition system (BIS) controls aversive motivation with sensitivity to negative outcomes.

As discussed earlier, our interest is in studying the effects of the regulatory foci resulting from positive versus negative reference points, the emphases on approach versus avoidance means, and the differences in motivation levels between them. Accordingly, we employ the BIS-BAS distinction to measure chronic sensitivity to the two regulatory foci. ${ }^{3}$ Note that because the BIS and BAS represent distinct physiological structures in the nervous system, their sensitivities are presumed to be independent (Quay, 1993; see also Higgins et al., 2001, for a similar conceptualization). Individuals may have any combination of high and low BIS and BAS.

Carver and White (1994) developed the BIS-BAS scales to measure Gray's (1990) regulatory systems, and we adopted these to operationalize BIS and BAS. Existing research has attested to the psychometric adequacy of these scales (Carver \& White, 1994; Heubeck, Wilkinson, \& Cologon, 1998). Note that other studies have used these scales to operationalize self-regulatory foci (Dholakia, Gopinath, \& Bagozzi, 2005; Leone, Perugini, \& Bagozzi, 2005; see also Carver \& Scheier, 1998, pp. 167-170; Gable, Reis, \& Elliot, 2000). These scales correlate highly with other instruments measuring chronic regulatory focus such as the Regulatory Focus Questionnaire (RFQ; Higgins et al., 2001). For example, Harlow, Friedman, and Higgins (1997) found a significantly positive correlation between the "Reward Responsiveness" subscale of the BAS (which we use in our study) and the RFQ's promotion score, and between the BIS scale (which we also use herein) and the RFQ's prevention score.

To summarize, in this study, we measure participants' regulatory focus (through the BAS and BIS scales) and then examine differences in desire experience and control between respondents with a promotion focus and respondents with a prevention focus. Unlike the first two studies, hypothetical consumption scenarios are employed in this study.

\footnotetext{
${ }^{3}$ Although BIS-BAS has been employed by other researchers to operationalize regulatory focus and it taps into several key aspects of the regulatory focus concept, we acknowledge that it is not a comprehensive characterization of the concept. We discuss other aspects of self-regulatory focus in greater depth in Study 4.
}

\section{Method}

\section{Participants and Procedure}

As a partial fulfillment of course requirements, 234 undergraduates participated in the study. Participants were first asked to select a purchase alternative in a scenario. Following this task, they completed a series of measures.

Scenario. The following scenario was employed. Participants were told:

\begin{abstract}
Ms. A is a 22-year old college student with a part-time job. It is two days before she gets the next paycheck and at present, she has only $\$ 25$ left for necessities in her bank account. In addition, she does have two credit cards that she sometimes uses. Today, Ms. A needs to buy a pair of warm socks for an outdoor party coming up this weekend. After work, she goes with her friend Ms. B to the mall to purchase the socks. As they are walking through Kaufmann's, Ms. A sees a great looking sweater on sale for $\$ 75$. The sweater is of a style that she has wanted to buy for a long time, and is in her favorite color. The helpful salesperson tells Ms. A that they have just one piece left in her size, and it is unlikely that they will get more pieces in this style in the future.
\end{abstract}

Participants were instructed to put themselves in Ms. A's place and then respond to the study measures.

\section{Measures}

Temptation enactment. Temptation enactment was measured by asking the participant, "Please indicate the probability that you would buy the sweater if you were Ms. $\mathrm{A}$ " using a scale ranging from 0 to 1.0 with .1 increments.

Thought listings. Participants were also instructed, "List the thoughts that went through your mind as you were reading the scenario, and thinking about what Ms. A should do." A maximum of five thoughts was elicited.

Desire. Desire intensity was measured by two items using 7-point scales. The first item asked participants to respond to, "I would feel a strong urge to buy the sweater if I were Ms. A." The second item asked participants to respond to, "If I were Ms. A, I would want to purchase the sweater." The mean of the two desire items was 4.92, and the standard deviation was 1.48 .

Self-control. Self-control was measured with two items. The first item was, "I would try to control myself if I were Ms. A." The second read, "I would try to resist my urge to buy the sweater if I were Ms. A." In each case, the participants indicated their responses on a 7-point scale ranging from 1 (strongly disagree) to 7 (strongly agree). The mean of the two self-control items was 5.02, and the standard deviation was 1.54 . 
Regulatory focus. Regulatory foci were measured using the BIS-BAS scale (Carver \& White, 1994) containing 20 items. The 7-item BIS scale operationalized prevention focus. The 5-item BAS-REWARD subscale measured the promotion focus, given its emphasis on the presence or absence of positive outcomes.

\section{Coding and Analysis}

The thought listings provided by respondents were coded by a single coder, blind to the predictions, as either "approach" or "avoidance" self-control strategies, or neither (cf. Kuhl, 1987).

An approach strategy was one framed with respect to resisting the desire, and defined as one involving movement toward this goal (e.g., "Socks are more important right now," "I care very much about my feet," "I will feel great later for walking away," and "I will enjoy the party more if I buy the socks"). An avoidance strategy was framed with respect to the temptation, and defined as one involving movement away from the temptation (e.g., "Will they have the same sweater at another store for less?" "I don't need this sweater," "I am sure they will get more sweaters later," and "I never wear sweaters more than once or twice anyway"). Note that thought listings were coded as "strategies" only when they were thoughts to engage in specific cognitive or physical actions to resist the temptation.

\section{Tests of Hypotheses}

Confirmatory factor analysis (CFA) was used to verify discriminant validity of the constructs. Differences in desire intensity, and the interactions of Desire $\times$ Self-Control $x$ Temptation Enactment to examine self-control efficacy were tested with multiple regression models. To investigate significant interactions, a simple effect analysis was done by running separate regression models for high and low levels of BIS and BAS. Because the samples involved in these analyses were smaller, to counter loss of statistical power, we used regression models computed within latent variable models to correct for measurement error (Jaccard \& Wan, 1995).

Structural equation modeling, employing LISREL 8.54, was used for the CFA and the latent-variable models (Jöreskog \& Sörbom, 1999). Their goodness-of-fit was as- sessed with chi-square tests, the root mean square error of approximation (RMSEA), the nonnormed fit index (NNFI), and the comparative fit index (CFI). Discussions of these indexes may be found in Bentler (1990), and Marsh, Balla, and Hau (1996). Satisfactory model fits are indicated by nonsignificant chi-square tests, RMSEA values less than .08, and NNFI and CFI values greater than or equal to .90 .

\section{Results}

CFA analysis. The CFA model built to test the discriminant validity of the model constructs had five latent constructs and 17 items, and fit the data well, $\chi^{2}(110, N=234)=$ $194.13, p \approx .00$ (RMSEA $=.05, \mathrm{NNFI}=.93, \mathrm{CFI}=.94)$. The factor loadings were all significant and high. Table 1 provides the $\phi$-matrix of the latent constructs (correlations between latent construct pairs, disattenuated for measurement error). Several correlations were statistically significant. However, all were significantly less than 1 , and only one was over .50 , providing evidence of discriminant validity of the constructs. The reliabilities were as follows: BIS $(\alpha=.78)$, BAS $(\alpha=.84)$, desire $(r=.80)$, and self-control $(r=.81)$. They were deemed satisfactory.

Desire intensity. Our first prediction was that desire would be more intense with a stronger promotion focus and less so for a stronger prevention focus. To test this hypothesis, the average of the two desire measures was regressed on BAS and BIS. These two predictors explained $8.8 \%$ of the variance in desire. Results reveal that BAS had a positive effect $(\beta=.30, p<.001)$ and BIS had a marginally significant negative effect $(\beta=-.11, p \approx .08)$, indicating that as expected, desire intensity increased with level of BAS and decreased with level of BIS of respondents.

Efficacy of self-control. To test our predictions regarding self-control efficacy, temptation enactment was regressed on desire, self-control, the two regulatory foci (BIS and BIS), and the two-way interactions between these variables. Note that because self-control is exerted only on experience of desire, it is important to control for effects of desire to determine self-control efficacy. The predictors explained $66.3 \%$ of the variance in temptation enactment. Unstandard-

TABLE 1

Correlation Matrix for the Five Latent Constructs: Study $3(N=234)$

\begin{tabular}{lcccc}
\hline & Desire & Self-Control & Temptation Enactment & BIS \\
\hline Desire & 1.00 & - & - & - \\
Self-control & $-0.59^{\mathrm{a}}$ & 1.00 & - & - \\
Temptation enactment & $0.36^{\mathrm{a}}$ & $-0.28^{\mathrm{a}}$ & 1.00 & - \\
BIS & 0.14 & 0.03 & 0.06 & - \\
BAS & $0.24^{\mathrm{a}}$ & 0.14 & 0.08 & 1.00 \\
\hline
\end{tabular}

Note. $\mathrm{BIS}=$ behavioral inhibition system; $\mathrm{BAS}=$ behavioral activation system.

aSignificantly greater than zero at $\alpha=.05$ level of significance. 
TABLE 2

Unstandardized Regression Coefficients, $t$ and $p$ Values for Explanation of Temptation Enactment: Study $3(N=230)$

\begin{tabular}{lrrl}
\hline & \multicolumn{1}{c}{$\beta$} & \multicolumn{1}{c}{$t$} & $p$ \\
\hline Desire & 0.93 & 3.33 & .00 \\
Self-control & -0.17 & -0.62 & $n s$ \\
BIS & -0.63 & -1.85 & .07 \\
BIS $\times$ Desirer & 0.38 & 1.52 & .13 \\
BIS $\times$ Self-Control & 0.58 & 2.54 & .01 \\
BAS & 0.76 & 3.70 & .00 \\
BAS $\times$ Desire & -1.03 & -2.86 & .00 \\
BAS $\times$ Self-Control & -0.92 & -2.90 & .00 \\
BIS $\times$ BAS & 0.17 & 0.48 & $n s$ \\
$R^{2}=66.3 \%$ & & & \\
\hline
\end{tabular}

Note, $\mathrm{BIS}=$ behavioral inhibition system; $\mathrm{BAS}=$ behavioral activation system.

ized regression coefficients and significance levels are provided in Table 2.

After controlling for the effects of desire, we predicted that self-control would interact with BIS and BAS. Results reveal desire and BAS had positive effects, and BIS had a negative effect, on temptation enactment. The higher the desire and the promotion focus (operationalized by BAS), the more respondents reported enacting their temptation, holding other variables in the model constant. Similarly, the higher the prevention focus (operationalized by BIS), the less respondents reported enacting their temptation, holding other variables constant. Note though that the main effects of BAS (and BIS) are included primarily as control variables, and we had no specific hypotheses regarding their direct effects on temptation enactment. The BIS-desire interaction was not significant $(\beta=$ $.38, p \approx .13$ ), but the BAS-desire interaction emerged as significant $(\beta=-1.03, p<.01)$. More important, interactions of Self-Control $\times$ Regulatory Foci (both) were significant $\left(\beta_{\mathrm{BIS} * \mathrm{SC}}=.58, p<.05\right.$ and $\left.\beta_{\mathrm{BAS} * \mathrm{SC}}=-.92, p<.01\right)$.
We interpreted the substantive meaning of these interactions using simple effect analyses. The whole sample was split in two different ways: once based on the median BIS score $(M d n=22)$ and the other based on the median BAS score $(M d n=21)$. We performed simple effect analysis using a latent variable modeling approach. In these models, measurement error is taken into account and hence regression parameter estimates are corrected for this error. The model tested for the four groups is shown in Figure 1.

The goodness-of-fit measures for the four models along with regression coefficients are provided in Table 3 . All models showed satisfactory fits. Note that our prediction regarding self-control efficacy implies that when BIS is low, desire should have less of an effect on temptation enactment than when its level is high. These differences emerged directionally, although not significantly. For BAS, the prediction suggests that the desire - temptation enactment coefficient should be bigger for the low-BAS level than for its high level. The results in Table 3 show that this is indeed the case, and these differences were significant.

The prediction also implies that the higher level of BIS sensitivity should attenuate the negative impact of self-control on temptation enactment. The opposite is implied for the self-control-BAS interaction on action. A significantly bigger negative coefficient is posited in the high BAS, relative to the low-BAS case. Again, the results of Table 3 support these predictions, significantly for BAS and directionally for BIS.

Analysis of self-control strategy thought listings. For the entire sample, an average of 2.4 strategies $(S D=1.7)$ was reported by participants. The total number of strategies reported did not vary by participants' regulatory focus $\left(M_{\text {promotion }}=2.32\right.$ vs. $\left.M_{\text {prevention }}=2.45\right), F(1,104)=.16, n s$. However, the type of strategies reported did differ. Promotion focused participants listed more approach strategies $\left(M_{\text {promotion }}=1.57\right.$ vs. $\left.M_{\text {prevention }}=.98\right), F(1,104)=5.02, p<$

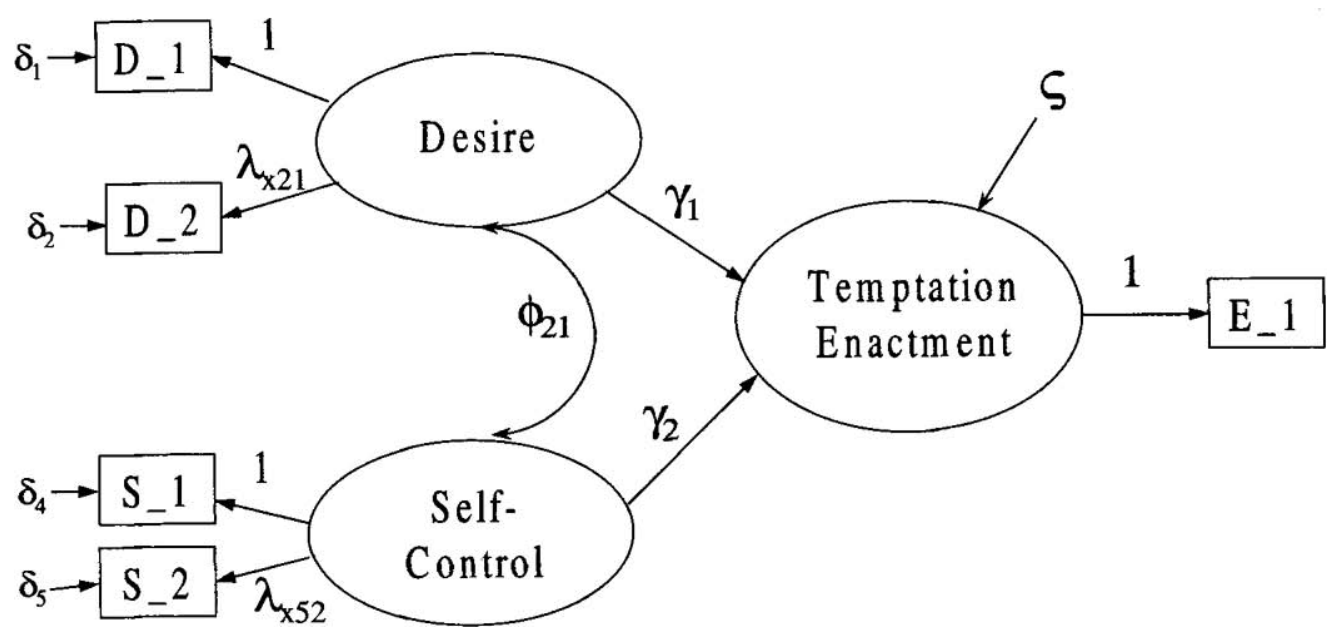

FIGURE 1 Model of the desire-temptation enactment and the self-control-temptation enactment interactions: A promotion versus prevention regulatory orientation is expected to moderate these two relations. 
TABLE 3

Goodness-of-Fit Measures and Regression Parameter Estimates for Latent Variable Models (Simple Effect analysis of the Desire and Regulatory Focus Interaction) and the Self-Control (Regulatory Focus Interaction: Study 3)

\begin{tabular}{|c|c|c|c|c|}
\hline & High BIS Group ${ }^{a}$ & Low BIS Group ${ }^{b}$ & High BAS Group ${ }^{a}$ & Low BAS Group $b$ \\
\hline \multicolumn{5}{|c|}{ Goodness-of-fit measures } \\
\hline$\chi^{2}(3)$ & $2.49, p=.48$ & $0.93, p=.82$ & $0.22, p=.97$ & $0.62, p=.89$ \\
\hline CFI & 1.00 & 1.00 & 1.00 & 1.00 \\
\hline NNFI & 1.00 & 1.00 & 1.00 & 1.00 \\
\hline RMSEA & 0.01 & 0.01 & 0.00 & 0.01 \\
\hline \multicolumn{5}{|c|}{ Regression parameter estimates } \\
\hline Desire & $.45^{*}$ & $.36 *$ & .13 & $.50 * \mathrm{c}$ \\
\hline Self-control & $-.42 *$ & $-.60^{*}$ & $-.74^{*}$ & $-.43 * \mathrm{c}$ \\
\hline$R^{2}$ & .63 & .72 & .71 & .66 \\
\hline
\end{tabular}

Note. BIS = behavioral inhibition system; BAS = behavioral activation system; CFI $=$ comparative fit index $; \mathrm{NNFI}=$ nonnormed fit index; RMSEA $=$ root mean square error of approximation.

${ }^{\mathrm{a}} N=109 .{ }^{\mathrm{b}} N=123$. ${ }^{\mathrm{c}}$ The coefficients are significantly different for the high and low subgroups.

$*_{p}<.01$.

.05 , and fewer avoidance strategies $\left(M_{\text {promotion }}=.75\right.$ vs. $\left.M_{\text {prevention }}=1.47\right), F(1,104)=10.81, p<.001$, than prevention focused participants, suggesting that regulatory focus influences which self-control strategies consumers use to resist temptations. ${ }^{4}$

\section{Discussion}

These results generally support our hypotheses that promotion focused consumers experience desire for temptations more intensely, yet are more successful in resisting the desire. They also provide preliminary evidence that participants in the two regulatory foci appear to use about the same number of self-control strategies in total. However, promotion focus individuals use more approach strategies, and those in a prevention focus use more avoidance strategies.

Despite joint support for the predictions, the limitations of the study must be pointed out. Although there were no interactions involving respondents' gender, the possibility that the protagonist's gender might influence the role of regulatory focus remains. In particular, because we used only a female protagonist in the scenario, male participants could have had difficulty relating to it. Relatedly, we did not ascertain the extent to which participants identified with the scenario, although informal poststudy conversations with participants indicated that they did identify.

Another limitation is that we used the BIS-BAS scales to operationalize regulatory focus in this study. We acknowledge that this operationalization captures only certain aspects of the regulatory focus concept; in particular the focus on positive outcomes in the promotion focus versus negative outcomes in the prevention focus cases. It does not consider other more subtle aspects of regulatory focus theory such as

\footnotetext{
${ }^{4}$ Mediation analysis did not reveal self-control strategies to mediate the differential effects of desire and self-control temptation enactment in BIS and BAS.
}

the concept of regulatory fit and its implications on self-control efficacy. We conducted Study 4 study to address these limitations and to better understand the processes that lead to differences in self-control efficacy in the two foci.

\section{STUDY 4: SITUATIONALLY INDUCED REGULATORY FOCUS AND PROCESSES UNDERLYING DESIRE EXPERIENCE AND SELF-CONTROL}

The use of different self-control strategies revealed by our post hoc analysis in Study 3 may be explained by the distinct orientations of consumers in the two foci: toward desire resistance for promotion focused consumers, and away from the temptation for prevention focused consumers. This prediction follows from Higgins's (2000) theory of regulatory fit, which suggests that the individual's regulatory focus influences his or her motivational and behavioral inclinations. In particular, promotion-focused individuals experience greater regulatory fit when they adopt approach-oriented means (i.e., means framed with respect to eagerness, achievement, and gain). Individuals with a prevention focus do so, on adopting avoidance-oriented means (i.e., means framed with respect to vigilance, caution, and loss; e.g., Freitas \& Higgins, 2002; Freitas, Liberman, \& Higgins, 2002).

After experiencing desire, even though all consumers are regulating away from the temptation, only prevention focused consumers are likely to frame their task in these terms. Regulatory fit theory suggests that promotion focused consumers are likely to frame their task differently, in terms of movement toward the goal of resisting desire (Higgins, Roney, Crowe, \& Hymes, 1994). In framing and using self-control strategies that approach the desire resistance goal, the outcome or outcomes of enacting the desire are less likely to be considered by promotion focused consumers.

Because prevention focused consumers use self-control strategies framed with respect to avoiding the temptation, 
cognizance of the tempting stimulus represents the starting point, with the control process formulated as a specific way of avoiding it. Avoidance strategies are framed around the temptation. Accordingly, we predict that these strategies will be less successful than approach strategies that ignore the tempting stimulus altogether and focus instead on the desire-resistance goal. In other words, it should be harder to self-regulate away from the temptation than toward the desire-resistance goal. If our logic is correct, then we expect these differences in the use of self-control strategies (i.e., more approach strategies by promotion focus individuals and more avoidance strategies by prevention focus individuals) to mediate differences in self-control efficacy between the two foci. This is a potential explanation for the moderating effects of self-regulatory focus on self-control that we found in Studies 2 and 3.

\section{Method}

Participants and procedure. To receive extra credit, 257 undergraduates participated in the experiment. Similar to Studies 1 and 2, this study was completed in two stages. Regulatory focus was primed in the first phase through essay writing using the same approach as the first two studies. Then in the second phase, participants were exposed to the scenario and completed measures similar to the first study. Note that to qualify for inclusion in the study, respondents had to identify with the purchase scenario (i.e., they had to provide a response of 4 or greater on a 7 -point agree-disagree scale to the statement, "It was easy to put myself in [the protagonist's] place when reading the scenario"). ${ }^{5}$

Scenario. In the second stage of the study, participants received a version of the following scenario describing a student of the same gender as the participant:

\begin{abstract}
Mr. (Ms.) Y is a 21-year-old college student. He (She) is twenty pounds overweight. On a weekday morning, Mr. (Ms.) $\mathrm{Y}$ decides to have a healthy salad for lunch. After a busy and productive morning at work, in which he (she) gets a lot accomplished, he (she) goes to Spizio's, his (her) favorite deli. As he (she) is looking though the display, he (she) sees a mouth-watering tray of strawberry cheesecake, his (her) favorite dessert and feels a strong craving for it immediately.
\end{abstract}

They were then told, "The situation faced by Mr. (Ms.) Y is one that individuals often experience. Please take a moment to put yourself in Mr. (Ms.) Y's place, and then answer the following questions."

\footnotetext{
${ }^{5} \mathrm{~A}$ very small number of participants who provided a response of less than four on the identification question was directed to complete another unrelated experiment through instructions given on the next page.
}

Measures. The measures used for desire, self-control, and temptation enactment were similar to Study 1. Participants also responded to, "If you were in Mr. (Ms.) Y's place, how would you describe your goal at the instant of making the decision?" The responses were coded and used to analyze participants' framing of the self-control task. Thought listings were also collected as in Study 1. Using 7-point scales ranging from 1 (not at all) to 7 (to a great extent), we collected the following two outcome measures: "On reading the scenario, to what extent were your thoughts initially about (a) the great taste and pleasure that would be derived from eating the cheesecake and (b) the guilt you would feel if you ate the cheesecake?"

Coding and analysis. Essays were judged for adequacy by two coders, blind to the hypotheses. An essay was deemed as adequate if it contained at least five sentences in support of the assigned principle. A total of 8 participants were dropped for not meeting this criterion. Eight other participants did not complete the study measures, leaving a total of 241 participants, which is the final sample for the study.

The two judges coded each participant's task description and thought protocols. The expressed self-control task was coded by the judges as "approaching the desire-resistance goal," "avoiding the temptation," or neither. Sample responses in the first category included, "to lose weight," "to eat a healthy salad," "to feel good about myself," and so forth, whereas those in the second category included, "to avoid eating the cheesecake," "to stay away from the temptation," and so forth. Thought protocols were coded as either approach self-control strategies, avoidance strategies, or neither. ${ }^{6}$ The two coders made a total of 833 decisions on thought protocols and agreed on $684(82.3 \%)$ of them. The 149 disagreements were mutually resolved in consultation with a third coder.

The 2 (Gender: Male or Female) $\times 2$ (Regulatory Focus: Promotion or Prevention) analyses of variance for desire intensity, self-control, and temptation enactment reveal no significant effects of gender on any of the dependent variables. Consequently, gender is not discussed further.

\section{Results}

Initial thoughts of respondents. One-way analyses of variance show that participants in the promotion focus condition indicated higher levels of agreement with having initial thoughts regarding taste and pleasure ( $M=5.3$ vs. 4.9$), F(1$,

\footnotetext{
${ }^{6}$ Examples of approach strategies included: "I would think about how good I would feel afterward," "I would think how I need to lose weight," "I would look at that slim person in line ahead of me," and so forth. Examples of avoidance strategies included, "I would look at the cheesecake and think how fattening it is," "I would stand away from the cheesecake tray," "I would tell myself that I would come back for cheesecake in the evening," and so forth. Details are available on request.
} 
$240)=6.18, p<.05$, but marginally lower levels of thoughts regarding guilt associated with eating the cheesecake $(M=$ 4.9 vs. 5.3$), F(1,240)=2.84, p<.10$, when compared to prevention focused participants.

Desire intensity. Results also show that promotion focused participants indeed reported a higher intensity of desire $(M=4.30)$ compared to prevention focused individuals $(M=3.99), F(1,239)=4.74, p<.05$, supporting the prediction.

Efficacy of self-control. To examine differences in self-control efficacy, we conducted a linear regression analysis of temptation enactment as a function of (a) self-regulatory focus, (b) desire, (c) self-control, and (d) two-way interactions. The predictors explained $46 \%$ of the variance in temptation enactment. Unstandardized regression coefficients and significance levels are provided in Table 4.

As can be seen, after controlling for the effects of desire, self-control had a negative effect on temptation enactment $(\beta$ $=-.16, p<.001) .{ }^{7}$ More important, the Regulatory Focus $x$ Self-Control interaction $(\beta=.04, p<.05)$ reveals a stronger negative effect of self-control on temptation enactment for those in a promotion focus than a prevention focus condition, supporting our prediction.

Number and type of self-control strategies used. Consistent with regulatory fit theory, we predicted that promotion focused individuals would use more approach self-control strategies, whereas prevention focused individuals would use more avoidance strategies. Results support this prediction: Promotion focused participants $(M=.90)$ reported significantly more approach strategies than prevention focused participants $(M=.67), F(1,238)=4.09, p<.05$. In contrast, prevention focused participants reported more avoidance strategies $(M=.82)$ than promotion focused participants $(M=.50), F(1,237)=7.78, p<.01$. Total strategies did not vary between the groups $\left(M_{\text {promotion }}=1.39\right.$ vs. $\left.M_{\text {prevention }}=1.48\right), F(1,237)=.32$, ns.

Mediating effects of self-control strategies on self-control efficacy. A mediation analysis, using the procedure suggested by Baron and Kenny (1986), was conducted to determine if use of approach and avoidance strategies mediated the differential effects of self-control in the two regulatory foci. To do so, number of approach strategies, number of avoidance strategies, and their two-way interactions with regulatory focus were added to the regression model. Results show that neither avoidance strategy coeffcient predicted enactment. However, the greater the number

\footnotetext{
${ }^{7}$ Considering that the cell means of self-control in the two regulatory foci conditions revealed a consistent pattern, with promotion focus participants reporting a higher level of self-control $(M=5.79)$ than prevention focus participants $(M=5.14, p<.005)$.
}

TABLE 4

Unstandardized Regression Coefficients, $t$ - and $p$-Values for Explanation of Temptations Enactment: Study $4(N=241)$

\begin{tabular}{lcrc}
\hline & $\beta$ & \multicolumn{1}{c}{$t$} & $p$ \\
\hline Desire & .02 & 0.35 & .72 \\
Self-control & -.16 & -5.02 & .00 \\
Regulatory focus & -.32 & -1.92 & .06 \\
Regulatory Focus $\times$ Desire & .04 & 1.33 & .18 \\
Regulatory Focus $\times$ Self-Control & .04 & 2.31 & .02 \\
$R^{2}=46 \%$ & & & \\
\hline
\end{tabular}

of approach strategies used, the lower the temptation enactment $(\beta=-.24, p<.001)$. A promotion focus further accentuated the effect of approach strategies on temptation enactment $(\beta=.03, p<.05)$. The two-way interaction between Regulatory Focus $\times$ Self-Control was no longer significant in explaining temptation enactment. Based on these results, it appears that the differences between the regulatory foci are driven primarily by the greater use of approach strategies by promotion focus consumers.

We then conducted a regression analysis of number of approach strategies as a function of self-control, regulatory focus, and the interaction between the two. Not surprisingly, those with higher self-control reported more approach strategies $(\beta=.34, p<.001)$, and the promotion focus further accentuated this effect $(\beta=-.23, p<.01)$. These results together indicate that the differential effects of self-control on temptation enactment in the two regulatory foci are fully mediated by the approach self-control strategies used by consumers.

Framing of the self-control task. We also examined how individuals framed their self-control task in the two foci. In the promotion focus condition, $48.1 \%$ of participants framed their task as "approaching the desire-resistance goal," whereas only $26.4 \%$ framed it as "avoiding the temptation." Results were reversed in the prevention focus condition. Here, only $20 \%$ of participants framed the self-control task as approaching desire resistance, whereas $55.6 \%$ framed it as temptation avoidance. These differences between the groups were significant, $\chi^{2}(2, N=241)=26.3, p<.001$.

\section{GENERAL DISCUSSION}

This research demonstrates that a consumer's regulatory focus plays an influential and subtle role in the experience and the control of desire for temptations. Consumers with a promotion focus are not only found to experience desire to a greater intensity but are able to more effectively resist such desires when compared to prevention focus consumers. These results add to the corpus of findings on regulatory focus by showing that a promotion focus relative to a prevention focus can actually in- 
hibit behavior when it conflicts with the individual's long-standing goals. Our analyses also show that these differences arise, in part, because the self-control task is framed differently by consumers under the two foci. Whereas promotion focused individuals tend to frame it as "to approach the desire-resistance goal," those with a prevention focus are more likely to frame it as "to avoid the temptation."

Interesting differences also arise between the two groups in the strategies they use to resist the desire. Although both groups used approximately the same number of strategies, consistent with regulatory fit theory (Higgins, 2000), promotion focused individuals tended to use strategies framed in the context of approaching the desire-resistance goal, and prevention focus individuals used more temptation avoidance strategies. An important finding is that approach strategies appear to be more successful in resisting temptations than strategies to avoid the temptation. This result may provide guidance to practitioners interested in stemming the enactment of deleterious temptations such as ones found in compulsive shopping, hoarding, gambling, eating disorders, and so forth.

One reason why avoidance strategies might be less effective is that they are devised with reference to the temptation, the salience of which may retard the efficacy of self-control. Another possibility is that the goal shifting process varies for consumers in the two foci. When the temptation is noticed, it becomes the focus first for all consumers. Following the desire's experience, the active goal then shifts to desire-resistance as the consumer becomes aware of the conflict. The motivational process guiding this shift in focus from the temptation to the desire-resistance goal may work such that it is faster for the promotion focused individuals relative to those with a prevention focus. This could explain why the consumer not only experiences a greater intensity of desire in the promotion focus (the shift to the temptation is quicker too), but is then able to resist it more effectively. This issue merits further attention.

Confidence in robustness of the findings is provided by a consistent pattern of findings (a) in studies involving real, tempting stimuli and hypothetical scenarios; (b) in different scenarios; and (c) in a dispositional and a situational operationalization of regulatory focus.

Despite the conceptual insights provided by this research, some of its limitations must be pointed out. We focused on one type of desire-those in which enactment realizes short-term pleasures, whereas inaction supports long-standing, long-term goals. We did not consider temporal construal explicitly. Although the situations examined are common in everyday life, in other cases, desires may favor inaction such as when the inclination not to enact effortful behavior conflicts with the longer term desire to accomplish some ideal. Desires to procrastinate when one must study or exercise are examples of such desires (see also Fishbach et al., 2003).

Our findings suggest that in such cases, promotion focused individuals should benefit by experiencing a greater desire to enact effortful behavior and also engage in more efficacious self-control. Those with a prevention focus, in contrast, should have a less intense desire to act and also be less able to control themselves. Examining this issue is an important extension to this research.

Future research should examine moderators of the effects uncovered here. As an example, in studying assigned goals such as solving math problems, Freitas et al. (2002) found that prevention focused participants outperformed promotion focused participants, and also enjoyed the tasks more, when they had to resist distracting video clips. In contrast, our research involving the conflict between temptations and personal goals revealed the opposite effects. The pattern of findings across the studies suggests that the type of goal that conflicts with the temptation, whether assigned or personally held, could moderate the effects of regulatory focus on temptation resistance. Previous experience and success with self-control could also act as a moderator of the effects found here.

The role of prior intentions and plans made by the individual to specifically counter the temptation is also important. Bratman (1996) noted that such counter-intentions of resistance "can have an independent role in rational motivation. Once in place, they can sometimes rationally control conduct even in the face of a temporary preference change to the contrary" (p. 304). One way in which counter-intentions may act is through inhibiting desire. Alternatively, they could influence the individual's cognitive processes. This issue warrants additional investigation.

Our focus in this article on the roles of desires in goal-directed, as opposed to mindless, consumer behavior must also be noted. We expect that desires play a central role for many types of mindless behaviors such as impulsive purchases or enactment of habitual actions (Dholakia et al., 2005), and many interesting opportunities exist to study this issue. For instance, it has been suggested that such "automatic cognitive processes" or "automatized action schemata" (Ainslie, 1992) can supercede the person's voluntary control. But relatively little is known regarding whether these "tightly integrated associative connections ... that always become active in response to a particular input configuration" (Tiffany, 1990 , p. 152) are learned through a motivated process, or the mechanisms through which such desires are generated. In addition, the role of "protoemotional" responses-that is, purely central, nonconscious responses to alluring stimuli as well as the expectancies for nonvolitional responses to such desires (Kirsch, 1999) — also merits attention. Studying the manner in which the individual's regulatory focus moderates these processes would be a nice complement to the research reported here.

In part because of our emphasis on motivational issues, we downplayed the role of emotions in the experience and resistance of desires for temptations. Being an integral part of desires (Belk, Ger, \& Askegaard, 2003), emotions are likely to play an important role throughout the process, from modu- 
lating the experienced desire's intensity, to regulating processes of self-control, through anticipated emotions.

\section{ACKNOWLEDGMENTS}

We wish to thank Lauren Bartel, Jeff W. Hansen, Ben Horne, Sangwon Lee, Rohit Mathur, Sudhakar Vissa, and Jared Wingard for help with data collection and analysis. We also thank three reviewers for helping to clarify and strengthen the contribution of this research.

\section{REFERENCES}

Aaker, J. L., \& Lee, A. Y. (2001) "I" seek pleasures and "we" avoid pains: The role of self-regulatory goals in information processing and persuasion. Journal of Consumer Research, 28(6), 33-49.

Ainslie, G. (1992). Picoeconomics: The strategic interaction of successive motivational states within the person. Cambridge, England: Cambridge University Press.

Baron, R. M., \& Kenny, D. A. (1986). The moderator-mediator variable distinction in social psychological research: Conceptual, strategic and statistical considerations. Journal of Personality and Social Psychology, 51, 1173-1182.

Baumeister, R. F., Heatherton, T. F., \& Tice, D. M. (1994). Losing control: How and why people fail at self-regulation. San Diego, CA: Academic.

Belk, R. W., Ger, G., \& Askegaard, S. (2003). The fire of desire: A multisited inquiry into consumer passion. Journal of Consumer Research, 30 , 326-351.

Bentler, P. M. (1990). Comparative fit indexes in structural models. Psychological Bulletin, 107, 238-246.

Bratman, M. E. (1996). Planning and temptation. In L. May, M. Friedman, \& A. Clark (Eds.), Mind and morals: Essays on cognitive science and ethics (pp. 293-310). Cambridge, MA: MIT Press.

Carver, C. S., \& Scheier, M. F. (1998). On the self-regulation of behavior. Cambridge, England: Cambridge University Press.

Carver, C. S., \& White, T. L. (1994). Behavioral inhibition, behavioral activation, and affective responses to impending reward and punishment: The BIS/BAS scales. Joumal of Personality and Social Psychology, 67, 319-333.

Crowe, E., \& Higgins, E. T. (1997). Regulatory focus and strategic inclinations: Promotion and prevention in decision making. Organization Behavior and Human Decision Processes, 69, 117-132.

Dholakia, U. M., Gopinath, M., \& Bagozzi, R. P. (2005). The role of desires in sequential impulsive choices. Organization Behavior and Human Decision Processes, 98, 179-194.

Fishbach, A., Friedman, R. S., \& Kruglanski, A. W. (2003). Leading us not unto temptation: Momentary allurements elicit overriding goal activation. Joumal of Personality and Social Psychology, 84, 296-309.

Freitas, A. L., \& Higgins, E. T. (2002). Enjoying goal-directed action: The role of regulatory fit. Psychological Science, 13, 1-6.

Freitas, A. L., Liberman, N., \& Higgins, E. T. (2002). Regulatory fit and resisting temptation during goal pursuit. Journal of Experimental Social Psychology, 38, 291-298.

Friedman, R. S., \& Förster, J. (2001). The effects of promotion and prevention cues on creativity. Journal of Personality and Social Psychology, 81, 1001-1013.

Gable, S. L., Reis, H. T., \& Elliot, A. J. (2000). Behavioral activation and behavioral inhibition in everyday life. Journal of Personality and Social Psychology, 78, 1135-1149.

Gray, J. A. (1990). Brain systems that mediate both emotion and cognition. Cognition and Emotion, 4, 269-288.
Harlow, R., Friedman, R. S., \& Higgins, E. T. (1997). The regulatory focus questionnaire. Unpublished manuscript, Columbia University, New York.

Heubeck, B. G., Wilkinson, R. B., \& Cologon, J. (1998). A second look at Carver and White's (1994) BIS/BAS scales. Personality and Individual Differences, 25, 785-800.

Higgins, E. T. (1999). Promotion and prevention as a motivational duality: Implications for evaluative processes. In S. Chaiken \& Y. Trope (Eds.), Dual-process theories in social psychology (pp. 503-528). New York: Guilford.

Higgins, E. T. (2000). Making a good decision: Value from fit. American Psychologist, 55, 1217-1230.

Higgins, E. T. (2002). How self-regulation creates distinct values: The case of promotion and prevention decision making. Joumal of Consumer Psychology, 12, 177-191.

Higgins, E. T., Friedman, R. S., Harlow, R. E., Idson, L. E., Ayduk, O. N., \& Taylor, A. (2001). Achievement orientations from subjective histories of success: Promotion pride versus prevention pride. European Journal of Social Psychology, 3I, 3-23.

Higgins, E. T., Roney, C. J. R., Crowe, E., \& Hymes, C. (1994). Ideal versus ought predilections for approach and avoidance-distinct self-regulatory systems. Journal of Personality and Social Psychology, 66(2), 276-286.

Higgins, E. T., \& Spiegel, S. (2004). Promotion and prevention strategies for self-regulation: A motivated cognition perspective. In R. F. Baumeister \& K. D. Vohs (Eds.), Handbook of self-regulation: Research, theory and applications (pp. 171-187). New York: Guilford.

Hoch, S. J., \& Loewenstein, G. F. (1991). Time-inconsistent preferences and consumer self-control. Journal of Consumer Research, 15, 492-507.

Jaccard, J., \& Wan, C. K. (1995). Measurement error in the analysis of interaction effects between continuous predictors using multiple regression: Multiple indicator and structural equation approaches. Psychological Bulletin, 117, 348-357.

James, W. (1890). The principles of psychology. New York: Holt.

Jöreskog, K., \& Sörbom, D. (1999). Lisrel 8: User's reference guide (2nd. ed.). Chicago: Scientific Software International.

Kirsch, I. (1999). How expectancies shape experience. Washington, DC: American Psychological Association.

Kuhl, J. (1987). Action control: The maintenance of motivational states. In F. Halisch \& J. Kuhl (Eds.), Motivation, intention and volition (pp. 279-291). Berlin, Germany: Springer-Verlag.

Leone, L., Perugini, M., \& Bagozzi, R. P. (2005). Emotion and decision making: Regulatory focus moderates motivational influence of anticipated emotions on attitudes. Cognition and Emotion, 19, 1175-1198.

Lewin, K. (1951). Intention, will and need. In D. Rapaport (Ed.), Organization and pathology of human thought (pp. 95-153). New York: Columbia University Press.

Liberman, N., Idson, L. C., Camacho, C. J., \& Higgins, E. T. (1999). Promotion and prevention choices between stability and change. Journal of Personality and Social Psychology, 77, 1135-1145.

Liberman, N., Molden, D. C., Idson, L. C., \& Higgins, E. T. (2001). Promotion and prevention focus on alternative hypotheses: Implications for attributional functions. Journal of Personality and Social Psychology, 80 , 5-18.

Marsh, H. W., Balla, J. R., \& Hau, K. (1996). An evaluation of incremental fit indices: A clarification of mathematical and empirical properties. In G. A. Marcoulides \& R. E. Schmacker (Eds.), Advanced structural equation modeling: Issues and techniques (pp. 315-353). Mahwah, $\mathrm{NJ}$ : Lawrence Erlbaum Associates, Inc.

Miller, N. E. (1951). Learnable drives and rewards. In S. S. Stevens (Ed.), Handbook of experimental psychology (pp. 435-472). New York: Wiley.

Pham, M. T., \& Avnet, T. (2004). Ideals and oughts and the reliance on affect versus substance in persuasion. Journal of Consumer Research, 30(4), $503-518$.

Quay, H. C. (1993). The psychobiology of undersocialized aggressive conduct disorder: A theoretical perspective. Development and Psychopathology, 5, 165-180. 
Roney, C. J., Higgins, E. T., \& Shah, J. (1995), Goals and framing: How outcome focus influences motivation and emotion. Personality and Social Psychology Bulletin, 21, 1151-1160.

Tice, D. M., Bratlavsky, E., \& Baumeister, R. F. (2001). Emotional distress regulation takes precedence over impulse control: If you feel bad, do it! Journal of Personality and Social Psychology, 80, 53-67.

Tiffany, S. T. (1990). A cognitive model of drug urges and drug-use behavior: Role of automatic and nonautomatic processes. Psychological Review, 97, 147-168.
Received: December 27, 2004

Revision received: June 6, 2005

Accepted: September 8, 2005 